\title{
New developments in the treatment of actinic keratosis: focus on ingenol mebutate gel
}

This article was published in the following Dove Press journal:

Clinical, Cosmetic and Investigational Dermatology

22 August 2012

Number of times this article has been viewed

\author{
Brian Berman \\ University of Miami Miller School \\ of Medicine, Miami, and Center for \\ Clinical and Cosmetic Research, \\ Aventura, FL, USA
}

\begin{abstract}
Actinic keratosis is a common disease in older, fair-skinned people, and is a consequence of cumulative ultraviolet exposure. It is part of a disease continuum in photodamaged skin that may lead to invasive squamous cell carcinoma. Treatment options frequently used include cryosurgery and topical pharmacologic agents, which are examples of lesion-directed and field-directed strategies. Ingenol mebutate gel was recently approved by the US Food and Drug Administration for topical treatment of actinic keratosis. While the mechanism of action of ingenol mebutate is not fully understood, in vitro and in vivo studies using tumor models indicate it has multiple mechanisms. Ingenol mebutate directly induces cell death by mitochondrial swelling and loss of cell membrane integrity preferentially in transformed keratinocytes. It promotes an inflammatory response characterized by infiltration of neutrophils and other immunocompetent cells that kills remaining tumor cells. The ability of ingenol mebutate to eliminate mutant p53 patches in ultraviolet-irradiated mouse skin suggests that it may have the potential to treat chronically ultraviolet-damaged skin. In human studies, ingenol mebutate achieved high clearance of actinic keratosis on the head and body after 2-3 consecutive daily treatments when measured by complete or partial clearance of lesions. Localized inflammatory skin responses were generally mild to moderate and resolved in less than a month.
\end{abstract}

Keywords: ingenol mebutate gel, actinic keratosis, field therapy, nonmelanoma skin cancer, protein kinase $\mathrm{C}$ delta

\section{Background}

Actinic keratosis (AK) is a commonly occurring skin disease in fair-skinned people of advanced age that results from cumulative ultraviolet irradiation. It is estimated that approximately $60 \%$ of people over the age of 40 years with a history of ultraviolet exposure have at least one AK lesion. ${ }^{1}$ A report that examined the burden of skin diseases prepared for the Society for Investigative Dermatology and the American Academy of Dermatology estimated that AK affects 58 million people in the US, leading to treatment costs greater than one billion dollars, based on 2004 prevalence estimates from multiple sources. ${ }^{2} \mathrm{AK}$ is most often clinically diagnosed by the presence of scaly, hyperkeratotic papules or plaques on sun-exposed surfaces such as the face, balding scalp, back of the hand, and forearms. When the possibility of invasive squamous cell carcinoma is of clinical concern, histopathologic examination of a biopsied sample is required to rule it out. ${ }^{3,4}$

AK is widely regarded as the initial clinical manifestation of a disease continuum in sun-damaged skin that may ultimately result in invasive squamous cell carcinoma. While AK is restricted to the epidermis, histopathologic analysis demonstrates that 
intraepidermal AK cells exhibit histopathologic features observed in invasive squamous cell carcinoma, including atypical keratinocytes, nuclear pleomorphism, and disordered keratinocyte maturation. ${ }^{3,5}$ Molecular studies of alterations in specific genes, such as p53, ${ }^{6} \mathrm{Myc},{ }^{7}$ epidermal growth factor receptor, ${ }^{8}$ and $\mathrm{p} 16^{\mathrm{INK} 4 \mathrm{a}},{ }^{9}$ as well as global changes in gene expression, ${ }^{10}$ confirm that $\mathrm{AK}$ and squamous cell carcinoma share a similar genetic evolutionary profile.

A specific AK lesion may regress, persist, or progress to invasive squamous cell carcinoma. While the estimated annual risk of progression of a single AK lesion is low, most patients with sun-damaged skin have many AK lesions, which increases their overall risk of invasive disease. ${ }^{11,12}$ Mathematical modeling of risk in a typical patient with an average of 7-8 AKs indicates a potential risk of invasive disease of $6.1 \%-10.2 \%$ over 10 years. ${ }^{13}$ Data suggest that the majority of squamous cell carcinomas arise from $\mathrm{AK}$; AK concomitant or contiguous with squamous cell carcinoma has been reported at high frequencies, ranging from $65 \%$ to $97 \% .^{12,14-16}$ One study reported that $36 \%$ of primary basal cell carcinomas diagnosed over 6 years of follow-up were associated with a previously diagnosed AK, indicating that AKs are also a marker of increased risk for basal cell carcinoma. $^{12}$

The rationale for treating AK is supported by histologic, molecular genetic, and epidemiologic evidence of the close relationship between $\mathrm{AK}$ and risk of squamous cell carcinoma. ${ }^{4,17,18}$ Treatment of AK is usually classified as lesion-directed or field-directed therapy. Cryosurgery with liquid nitrogen is a procedurally rapid and generally accepted effective method for treating isolated lesions that are few in number, and it is the most frequently used method in the US. ${ }^{19-21}$ Hypopigmentation not infrequently follows healing after the extended freezing times needed for high efficacy. ${ }^{22}$ Because this approach does not treat perilesional skin, significant recurrence has been observed. ${ }^{23}$ In patients with severely sun-damaged skin, perilesional skin may contain many subclinical AKs due to ultraviolet light-induced field cancerization; the resulting genetic and histopathologic changes in ultraviolet-irradiated keratinocytes have the potential to become clinically visible lesions. ${ }^{24,25}$

Field cancerization is treated with ablative methods, such as dermabrasion and chemical peels, as well as photodynamic therapy and topical creams and gels containing pharmacologic agents that lead to elimination of transformed cells. Until recently, topically applied pharmacologic field therapies have included 5-fluorouracil, imiquimod, and diclofenac. Clearance of lesions that become evident during treatment, in addition to baseline lesions (those present at the start of treatment), demonstrates the efficacy of these agents for subclinical lesions. ${ }^{24,26,27}$ These products are generally used for several weeks and cause localized inflammation, leading to erythema, burning, and ulceration, which may challenge a patient's ability to adhere to the regimen. Strategies introduced to improve the tolerability of topical treatments include modified dosing schedules, reduced concentration of the pharmacologic agent, and novel formulations. ${ }^{27-29}$

Current approaches to the management of AK use both lesion-directed and field-directed methods as a strategy to increase the overall success of treatment. ${ }^{30}$ Sequential treatment with photodynamic therapy followed by imiquimod, ${ }^{31}$ cryosurgery followed by diclofenac ${ }^{32}$ or by imiquimod, ${ }^{33,34}$ and brief pretreatment with 5 -fluorouracil prior to cryosurgery ${ }^{35}$ have demonstrated the success of this strategy.

A new topical field therapy for AK, ingenol mebutate gel $(0.015 \%, 0.05 \%)$, was recently approved by the US Food and Drug Administration. The $0.015 \%$ gel formulation is used once daily on the face or scalp for three consecutive days, while the $0.05 \%$ gel formulation is used once daily on the trunk or extremities for two consecutive days. ${ }^{36}$ This article reviews the pharmacology and preclinical studies of ingenol mebutate and highlights the clinical studies that support the efficacy and safety of ingenol mebutate for the treatment of AK.

\section{Discovery of ingenol mebutate}

Ingenol mebutate is a diterpene ester (chemical structure shown in Figure 1) extracted and purified from the plant Euphorbia peplus. The sap of this plant, also known as petty surge or radium weed, has a history of use as an alternative therapy for skin diseases. ${ }^{37,38}$ In a 1986 random sample of approximately 2000 residents of Nambour, Australia, 164 respondents indicated that they self-treated skin cancers and AKs. ${ }^{38}$ Among the naturopathic agents used, the sap of E. peplus provided consistent efficacy. ${ }^{38}$ The efficacy of this

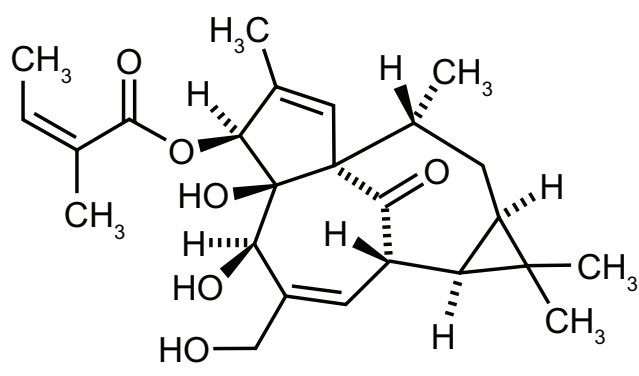

Figure I Chemical structure of ingenol mebutate, $\mathrm{C}_{25} \mathrm{H}_{34} \mathrm{O}_{6}$. 
sap was confirmed in a clinical study of three daily treatments of 48 lesions that included intraepidermal carcinoma, basal cell carcinoma, and squamous cell carcinoma. The complete clinical clearance of more than $50 \%$ of lesions after a mean follow-up time of 15 months supported further clinical development of ingenol mebutate. ${ }^{39}$

\section{Pharmacology of ingenol mebutate}

The pharmacology of ingenol mebutate, while not fully elucidated, has been studied in in vitro and in vivo models of carcinogenesis. In the absence of an animal model for human AK disease, studies have utilized mouse tumor models of skin cancer and several tumor cell lines. These studies indicate that the efficacy of ingenol mebutate involves multiple mechanisms. At high concentrations, there is initial rapid and direct cell death; this is followed by a second phase involving a complex inflammatory response. Penetration of tritium-labeled ingenol mebutate was examined in a cultured, reconstructed full-thickness model of human skin. ${ }^{40}$ The labeled compound was distributed over the full depth of the skin in a gradient, with the highest concentration in the epidermal structures and the lowest concentration in the dermal component. ${ }^{40}$

\section{Primary cell necrosis}

The acute cytotoxic effects of a high concentration (about $100 \mu \mathrm{M}$ ) of ingenol mebutate were observed in vitro within hours after treatment of B16 mouse melanoma cells. ${ }^{41}$ Loss of mitochondrial membrane potential, mitochondrial swelling, and rapid loss of plasma membrane integrity leading to cell death within hours were observed, as schematically depicted in Figure 2A. ${ }^{40-42}$ Similar cellular disruption was observed 24 hours after application to B16 mouse melanoma tumors established in vivo in mice. ${ }^{41}$ It is postulated that ingenol mebutate causes calcium release from the endoplasmic reticulum (rather than an influx of extracellular calcium), further calcium loss from the mitochondria, and plasma membrane disruption leading to death. ${ }^{41,42}$ A recent presentation demonstrated that human keratinocytes differentiated by the presence of high calcium were significantly less sensitive to ingenol mebutate-mediated cell death than were proliferating keratinocytes. ${ }^{42}$

Treatment with three daily doses of $42 \mathrm{nM}$ ingenol mebutate cured subcutaneous tumors, initiated from tumor cell lines, grown in Foxn $1^{n u}$ or C57BL/6 mice. ${ }^{41}$ An acute erythema lasting 2-3 hours occurred after treatment of all tumor types, followed by eschar formation and healing at one month. C57BL/6 mice remained free of B16 tumors at 94 days of follow-up. ${ }^{41}$

\section{Inflammatory response}

Low concentrations of ingenol mebutate lead to activation of protein kinase $\mathrm{C}$ delta $(\mathrm{PKC} \delta$ ) and contribute to the inflammatory processes that eliminate $\mathrm{AK} .{ }^{43}$ Ingenol mebutate is proapoptotic in several tumor cell lines ${ }^{44-46}$ by a process that includes activation and translocation of PKC $\delta$ from the cytoplasm to the nucleus. ${ }^{43,44}$ Ingenol mebutate-mediated $\mathrm{PKC} \delta$ activation is also associated with immunostimulatory effects that include production and release of inflammatory cytokines, such as interleukin- $6 .{ }^{43}$

Topical administration of ingenol mebutate to sites of tumors in murine models of skin cancer produced a localized, neutrophil-rich, inflammatory infiltrate within hours. ${ }^{47}$ In the Foxn $1^{n u}$ mouse model, this neutrophil response must remain intact to prevent tumor relapse. ${ }^{47}$ When neutrophil activity was eliminated in this model and a second model, the CD18-deficient mouse, reduced inflammation and significantly increased tumor relapse rates $(>70 \%)$ were observed over several weeks. ${ }^{47}$

The ability of ingenol mebutate to penetrate the dermis, where it can act on deeply imbedded tumor cells, may contribute to successful elimination of tumor cells. ${ }^{48}$ Experiments with structurally distinct modulators of P-glycoprotein demonstrate that ingenol mebutate binds to and is a transport substrate for P-glycoprotein, which facilitates its transport to subepidermal compartments. ${ }^{48}$

The rapid inflammation induced by ingenol mebutate was associated with induction in vivo of macrophage inflammatory protein-2, tumor necrosis factor-alpha (TNF- $\alpha$ ), and interleukin-1 $\beta$, ie, proinflammatory cytokines detected in mouse skin that mediate neutrophil recruitment and activation. ${ }^{47}$ In vitro studies demonstrated that ingenol mebutate also induced interleukin- 8 , the human equivalent of macrophage inflammatory protein-2, in normal human keratinocytes, fibroblasts, melanoma cells, and neutrophils, and TNF- $\alpha$ in keratinocytes. ${ }^{47}$ Ingenol mebutate also stimulated release of TNF- $\alpha$ from cultured proliferating keratinocytes. ${ }^{40}$ In a separate study, TNF- $\alpha$ was associated with induction of death ligand-mediated apoptosis that occurred upon treatment of squamous cell carcinoma cell lines with diclofenac. ${ }^{49}$ It is postulated that ingenol mebutate-dependent stimulation of TNF- $\alpha$ may contribute to the killing of neighboring cells of squamous cell carcinoma origin by activation of death receptor pathways.

Recruitment of neutrophils to sites of inflammation occurs by migration across vascular endothelial cells lining the postcapillary venules. Ingenol mebutate stimulated local production of cytokines which recruited neutrophils 


\section{A}

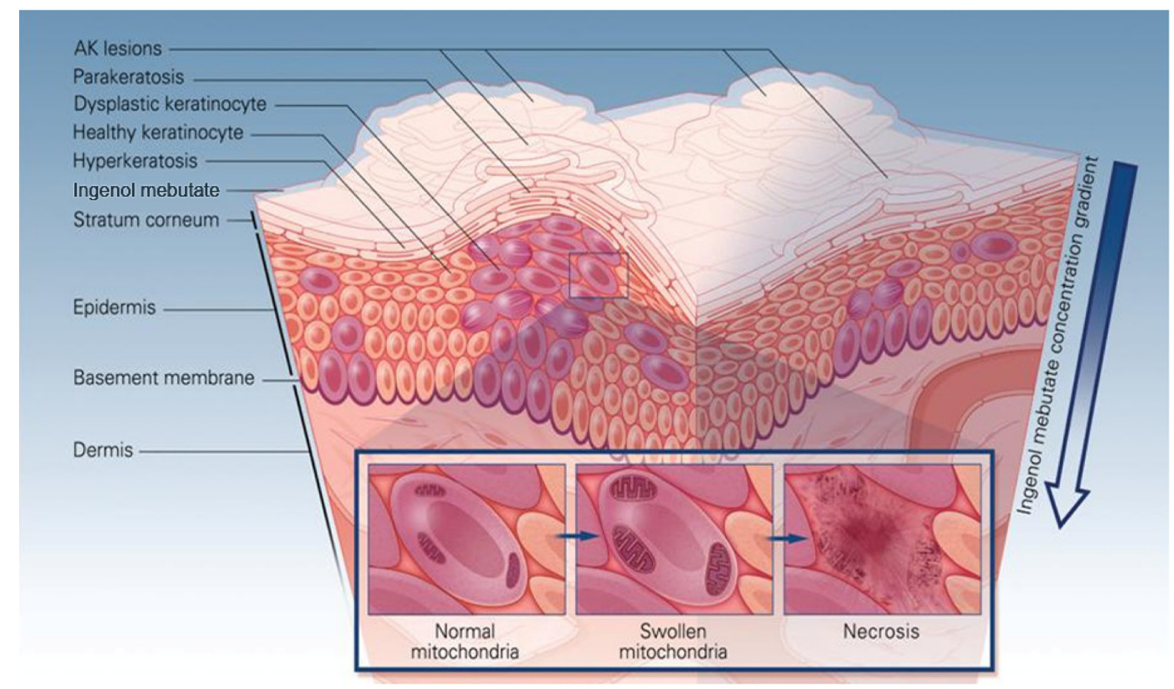

(C) LEO Pharma Inc.;2012

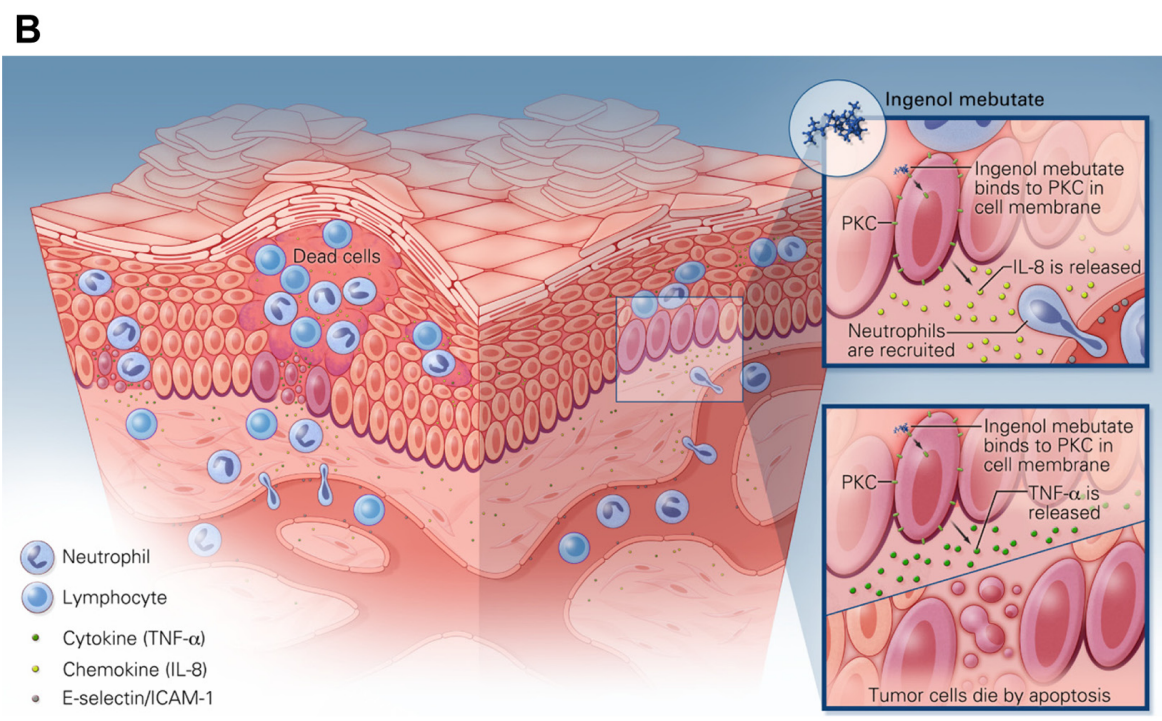

(c) LEO Pharma Inc.; 2012

Figure 2 Schematic model of proposed mechanisms of ingenol mebutate. (A) Ingenol mebutate penetrates skin in a gradient-dependent manner ${ }^{40}$ whereby it preferentially induces death in proliferating undifferentiated cells ${ }^{42}$ by increases in intracellular calcium, mitochondrial swelling, and loss of cell membrane integrity. ${ }^{41}$ (B) Cell death and protein kinase $\mathrm{C}$ activation lead to an inflammatory activation of the treated field. Ingenol mebutate increases local production of tumor necrosis factor-alpha and interleukin-8, which recruit and activate neutrophils ${ }^{40,47}$ and directly activate endothelial cell expression of the adhesion receptors E-selectin and intercellular adhesion molecule-1..$^{50}$

to endothelial cells. ${ }^{47}$ In addition to this paracrine route, ingenol mebutate appeared to activate endothelial cells directly by a PKC $\delta$-dependent mechanism, further supporting neutrophil recruitment. Treatment of endothelial cells with ingenol mebutate increased expression of the adhesion receptors E-selectin and intercellular adhesion molecule-1, and the neutrophil chemoattractant interleukin- 8 , in a dosedependent manner. ${ }^{50}$ In a physiologic flow-based adhesion assay, ingenol mebutate stimulated neutrophil adhesion to endothelial cell monolayers that was blocked by antibody to E-selectin. ${ }^{50}$
The ability of ingenol mebutate to activate multiple isoforms of protein kinase $\mathrm{C}$ prompted investigation of the role of protein kinase $\mathrm{C}$ activation in endothelial cells. ${ }^{43}$ Analysis of stimulated protein kinase $\mathrm{C}$ isoenzyme expression, Western blot protein studies, and siRNA knockdown experiments demonstrated that activation of PKC $\delta$ in endothelial cells is responsible for the direct effects of ingenol mebutate on endothelial cells that contribute to neutrophil recruitment. ${ }^{50}$ The immune activation effects are illustrated in Figure 2B. ${ }^{40,47,50}$ 
Further mouse experiments provide several lines of evidence that antibody-dependent cellular cytotoxicity may contribute to the ability of neutrophils to kill tumor cells. First, tumors treated with ingenol mebutate showed a high relapse rate in SCID mice lacking a humoral immune response. ${ }^{47}$ Second, anticancer antibodies against B16 tumors were isolated from tumor-bearing ingenol mebutate-treated animals, but not from untreated animals, indicating that ingenol mebutate stimulates production of anticancer antibodies. ${ }^{47}$ The third observation implicating antibody-dependent cellular cytotoxicity in relapse prevention was the ability of antiserum from ingenol mebutate-treated tumor-bearing Foxn $1^{n u}$ mice to reduce the viability of LK tumor cells (an ultravioletinduced mouse squamous cell carcinoma cell line) in vitro in the presence of murine neutrophils and added complement. ${ }^{47}$ It should be noted that these observations were made in a murine model and that the presence and contribution of antibody-dependent cytotoxicity in the clearance of AKs from human skin remains unknown.

Additional therapeutic anticancer efficacy of ingenol mebutate may be conferred by activation of additional protein kinase $\mathrm{C}$ isoforms. Local treatment of subcutaneous B16 tumors was recently reported to produce specific $\mathrm{T}$ cell responses. ${ }^{51}$ Intratumoral treatment of primary tumors induced anticancer $\mathrm{CD} 8^{+} \mathrm{T}$ cell activity that caused regression of distant secondary tumors. ${ }^{51}$ It also promoted survival of $\mathrm{CD}^{+} \mathrm{T}$ cells that was dependent on activation of $\mathrm{PKC} \theta$, a protein kinase $\mathrm{C}$ isoform expressed in high levels in T cells. ${ }^{52}$

These studies demonstrate that ingenol mebutate eliminates visible subcutaneous tumors by immediate cytotoxicity and a neutrophil-dependent inflammatory response that protects against tumor relapse. A study of ultraviolet-induced tumors in the hairless SKH1/hr mouse model demonstrated that two days of topical application to photodamaged skin reduced the number of skin lesions that subsequently developed over 21 weeks by approximately $70 \%$ (Figure $3 \mathrm{~A}$ ). ${ }^{53}$ At the end of 21 weeks, the skin of treated mice felt and appeared normal. Approximately $4-5$ weeks after the mouse skin had healed following treatment with ingenol mebutate, the skin was excised and analyzed for expression of mutant p53 in newly formed epidermis. Active treatment significantly reduced the number of mutant p53 keratinocyte patches by $70 \%$, compared with untreated and placebo-treated mice (Figure $3 \mathrm{~B}$ ).$^{53}$ Because mutations in p53 are thought to be an early event in the formation of AK and squamous cell carcinoma, ${ }^{6}$ these findings suggest that ingenol mebutate may be useful for removal of subclinical precancerous cells from sun-damaged skin.
A separate in vitro study of human fibroblasts suggests that ingenol mebutate induces collagen turnover and increases production of one of the important skin matrix building blocks, hyaluronic acid. This may contribute to the healing process and the observed good cosmetic outcome in the clinical studies. ${ }^{54}$

\section{Clinical studies of ingenol mebutate Phase II studies}

Siller et al conducted a randomized, double-blind, vehiclecontrolled, Phase IIa study evaluating the safety and efficacy of two applications of ingenol mebutate gel in 58 patients with biopsy-confirmed AK of the arms, shoulder, chest, and face or scalp. ${ }^{55}$ Five preselected lesions were treated by a direct application of ingenol mebutate $0.0025 \%, 0.01 \%$, $0.05 \%$, or vehicle gel on days 1 and $2(\operatorname{arm} \mathrm{A})$ or days 1 and 8 (arm B). Because there were no significant differences in efficacy and safety responses between the two application schedules, the data were combined. The highest rates of clinical lesion clearance at day 85 were obtained with ingenol mebutate $0.05 \%$, resulting in complete clearance of $71 \%$ of treated lesions $(P<0.0001$ versus vehicle); $67 \%$ of patients achieved $\geq 80 \%$ clinical clearance of their lesions. ${ }^{55}$ The most common local skin reactions reported in patients in the ingenol mebutate $0.05 \%$ group were erythema (87\%), flaking/scaling/dryness (87\%), and scabbing/ crusting (67\%). Local skin reactions were generally mild or moderate in severity, with eight patients experiencing a severe local skin reaction. Local skin reactions resolved by the end of the study, with one exception of scabbing that was ongoing at day $85 . .^{55}$

Anderson et al studied ingenol mebutate gel for treatment of non-facial AKs in a Phase IIb, randomized, double-blind, double-dummy, vehicle-controlled trial in 222 patients. ${ }^{56}$ Ingenol mebutate $0.025 \%$ gel was applied for three consecutive days and $0.05 \%$ was applied for two or three consecutive days. Patients had 4-8 clinically apparent AKs in a contiguous $25 \mathrm{~cm}^{2}$ area. The lesions were distributed predominantly on the arm (66.2\%) and scalp (27.5\%), with the remainder on the chest, shoulder, and back. Patients were assessed at days $3,8,15,29$, and 57 (end of study) for adverse events and local skin reactions. The primary efficacy endpoint was the partial clearance rate, defined as the proportion of patients at 57 days with $\geq 75 \%$ reduction in the number of AKs compared with baseline. Secondary endpoints included the complete clearance rate (proportion of patients with no visible AKs), the baseline clearance rate (proportion with $100 \%$ reduction of the AKs identified at baseline), and the percentage reduction of AKs from the number of baseline lesions. 

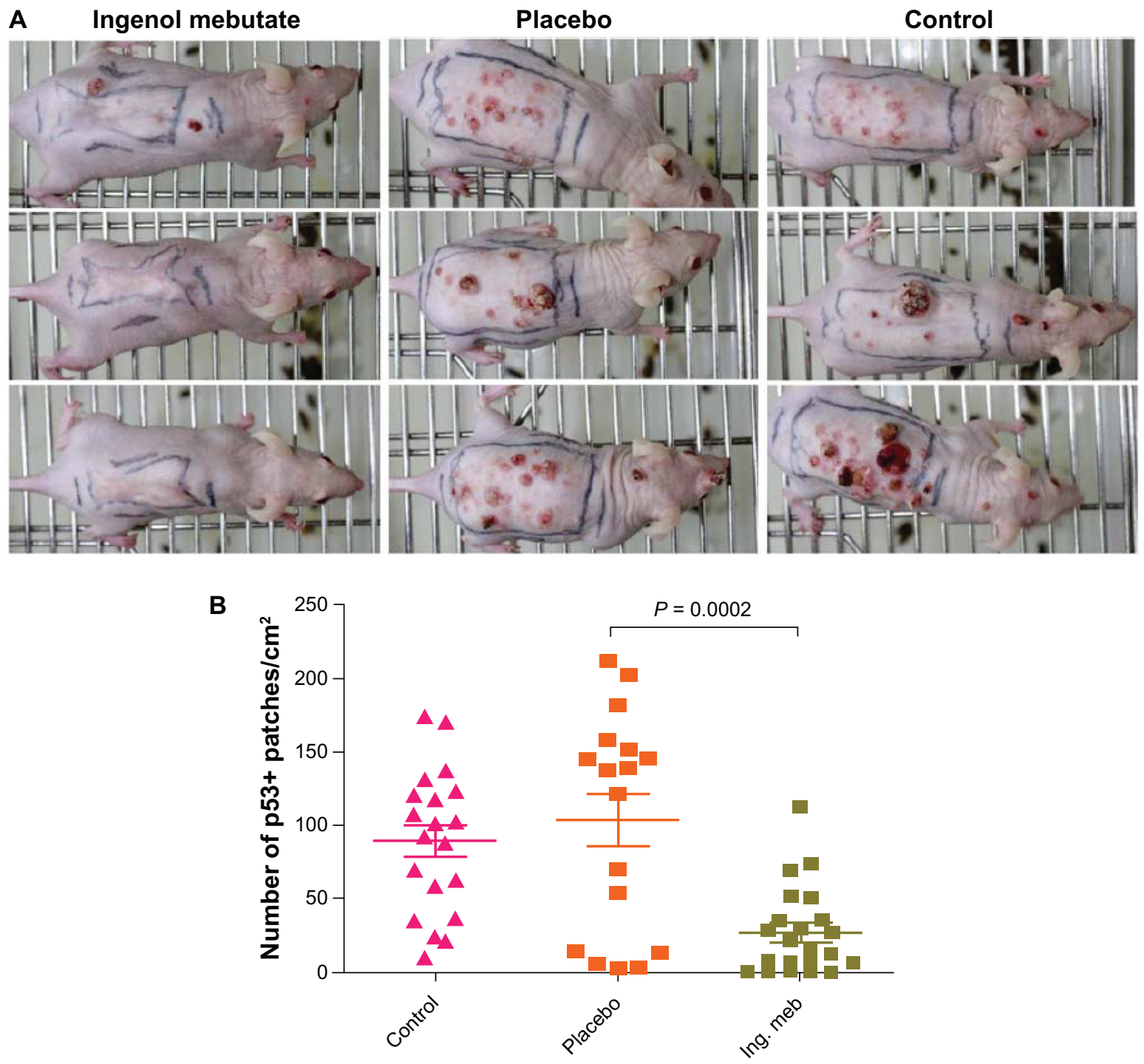

Figure 3 Treatment of skin in ultraviolet B-irradiated SKHI/hr mice with ingenol mebutate $0.05 \%$ gel reduced the number of skin lesions and mutant $\mathrm{p} 53$ patches that subsequently developed compared with placebo and no treatment. After 30 doses of ultraviolet B radiation, mice were untreated (control) or treated with placebo gel or ingenol mebutate $0.05 \%$ gel on days 0 and 2. (A) Representative mice from ingenol mebutate, placebo, and control groups taken at $2 \mathrm{I}$ weeks after treatment initiation. (B) The number of mutant $\mathrm{p} 53$ patches analyzed by immunohistochemistry in the skin of ultraviolet B-irradiated mice. Each symbol represents an individual mouse, and bars indicate the mean \pm standard error of the mean.

Copyright (C) 2012. Nature Publishing Group. Reprinted with permission from Cozzi SJ, Ogbourne SM, James C, et al. Ingenol mebutate field-directed treatment of UVB-damaged skin reduces lesion formation and removes mutant $\mathrm{p} 53$ patches. J Invest Dermatol. 2012;132(4):1263-127I. ${ }^{53}$

All three active treatments were significantly more effective than vehicle (overall $P<0.0001$ ) for all measures of efficacy; the treatment effects were also dose-dependent. For the primary endpoint, $75.4 \%, 61.8 \%$, and $56.0 \%$ of patients from the three cohorts $(0.05 \%$ for three days, $0.05 \%$ for two days, and $0.025 \%$ for three days, respectively) met the criteria of $\geq 75 \%$ reduction in number of AKs versus baseline. Local skin reactions were most intense between days 3 and 8 , as anticipated based on the mechanism of action of ingenol mebutate. At day 8 , erythema and flaking/scaling were reported in approximately $96 \%$ of patients. All three active treatments were well tolerated, with local skin reactions resolving spontaneously within 2-4 weeks after treatment. No patients discontinued the study due to adverse events. There was no treatment-emergent scarring, and no serious treatment-related adverse events occurred during the study. Patients' ratings of their satisfaction with treatment was significantly higher for ingenol mebutate than for vehicle for healing time, cosmetic outcome, comparison with patients' previous AK treatments, and overall satisfaction (all $P<0.001) .{ }^{56}$ These Phase II studies show that a short course of topical ingenol mebutate gel is an effective treatment for 
AK with a favorable safety profile. These data supported the evaluation of this agent in larger Phase III studies.

\section{Phase III studies Methods}

Ingenol mebutate was evaluated for the treatment of AK in four multicenter, randomized, double-blind, vehiclecontrolled Phase III studies. ${ }^{57}$ Two studies $(\mathrm{n}=547)$ examined ingenol mebutate $0.015 \%$ gel versus vehicle gel applied for three days to AKs on the face or scalp, and two studies $(\mathrm{n}=458)$ investigated ingenol mebutate $0.05 \%$ gel versus vehicle gel applied for two days to AKs on the trunk or extremities. Patients were required to have 4-8 AKs in a $25 \mathrm{~cm}^{2}$ contiguous area of intact skin. Patients with hypertrophic or recalcitrant lesions were excluded. The study protocol prohibited recent use of immunosuppressive or immunomodulatory medications, cytotoxic drugs, or AK therapies that might interfere with treatment evaluation. The mean age of the patients was 65.1 years; the majority had Fitzpatrick skin types I and II, approximately half had a history of skin cancer, and $>75 \%$ had undergone previous cryosurgery. Patients were assessed for local skin reactions and adverse events at baseline and at days 3, 4 (one day after the last gel application), 8, 15, 29, and 57. Clearance of AK was evaluated at day 57 and included the primary endpoint, complete clearance of all visible lesions, and the secondary endpoints of partial clearance (defined as $\geq 75 \%$ reduction in lesion count compared with baseline) and percentage change from baseline in the total number of AKs. In the ingenol mebutate groups, approximately $98 \%$ of patients applied all doses of medication..$^{57}$

\section{Efficacy}

Efficacy results were pooled for the two face or scalp studies and for the two trunk or extremity studies (Table 1). The proportion of patients who achieved complete clearance of all AK lesions was significantly higher with ingenol mebutate compared with vehicle for all pooled analyses $(P<0.001)$ : face or scalp studies, $42.2 \%$ versus $3.7 \%$; and trunk or extremities, $34.1 \%$ versus $4.7 \% .{ }^{57}$ Similarly, partial clearance rates were significantly higher with active treatment for studies of both anatomical regions $(P<0.001)$. The median reduction in lesion count was $83 \%$ with ingenol mebutate $0.015 \%$ gel and $75 \%$ with $0.05 \%$ gel, compared with a median reduction of $0 \%$ in both corresponding vehicle groups.$^{57}$ Results for the primary endpoint of complete clearance were also highly significant, favoring ingenol mebutate in each of the four individual studies $(P<0.001){ }^{57}$
Table I Proportion of patients with complete or partial clearance and median reduction in number of lesions at day 57 (pooled analyses)

\begin{tabular}{|c|c|c|}
\hline Face or scalp & $\begin{array}{l}\text { Ingenol mebutate, } 0.015 \% \\
(n=277)\end{array}$ & $\begin{array}{l}\text { Vehicle } \\
(n=270)\end{array}$ \\
\hline Complete clearance rate & 42.2 & 3.7 \\
\hline $\begin{array}{l}\text { Partial clearance rate } \\
\text { ( } \geq 75 \% \text { of lesions) }\end{array}$ & 63.9 & 7.4 \\
\hline $\begin{array}{l}\text { Median reduction in } \\
\text { number of lesions, \%* }\end{array}$ & 83 & 0 \\
\hline Trunk or extremities & $\begin{array}{l}\text { Ingenol mebutate, } 0.05 \% \\
(n=226)\end{array}$ & $\begin{array}{l}\text { Vehicle } \\
(n=232)\end{array}$ \\
\hline Complete clearance rate & 34.1 & 4.7 \\
\hline $\begin{array}{l}\text { Partial clearance rate } \\
\text { ( } \geq 75 \% \text { of lesions) }\end{array}$ & 49.1 & 6.9 \\
\hline $\begin{array}{l}\text { Median reduction in } \\
\text { number of lesions, } \%^{\dagger}\end{array}$ & 75 & 0 \\
\hline
\end{tabular}

Notes: ${ }^{*} \mathrm{n}=273$, ingenol mebutate; $\mathrm{n}=269$, vehicle; ${ }^{\dagger} \mathrm{n}=220$, ingenol mebutate; $\mathrm{n}=229$, vehicle.

Copyright () 2012. Massachusetts Medical Society. Reprinted with permission from Massachusetts Medical Society from Lebwohl M, Swanson N, Anderson LL, Melgaard A, Xu Z, Berman B. Ingenol mebutate gel for actinic keratosis. N Engl J Med. 2012;366(II):1010-1019.57

The efficacy of ingenol mebutate varied according to anatomic location, with higher rates of complete clearance associated with facial AK (ingenol mebutate versus vehicle, 47.3\% versus $4.1 \% ; P<0.001$ ) than with scalp lesions (ingenol mebutate versus vehicle, $22.8 \%$ versus $2.0 \% ; P=0.001) .{ }^{58}$ In the trunk or extremity studies, the proportion of patients with complete clearance of lesions was lower for lesions of the arm (ingenol mebutate versus vehicle, $34.5 \%$ versus $4.7 \% ; P<0.001)$ and back of the hand (ingenol mebutate versus vehicle, $18.5 \%$ versus $0 \% ; P=0.001$ ) than for those with lesions at other sites (ingenol mebutate versus vehicle, $60.0 \%$ versus $14.8 \% ; P<0.001) .{ }^{59}$

Patients who achieved complete clearance at 57 days were eligible for assessment in two long-term, 12-month observational studies. Among the 108 patients in the face or scalp studies, 53.9\% (95\% confidence interval 44.6-63.7) experienced development or recurrence of one or more lesions, for a lesion-based recurrence rate of $12.8 \%$ from the original baseline. Long-term follow-up of 38 patients with complete clearance from the trunk or extremity studies demonstrated appearance of at least one AK lesion in $50 \%$ of cases $(95 \%$ confidence interval 35.5-66.6), for a lesion-based recurrence rate of $14.9 \%$ from the original baseline. ${ }^{57}$

\section{Safety}

Local skin reactions were assessed using defined photographic guides and were graded on a severity scale of $0-4$, with higher numbers indicating greater severity. Local skin 
reactions were evaluated for the six parameters of erythema, flaking or scaling, crusting, swelling, vesiculation or pustulation, and erosion or ulceration. A composite score of 0-24 was calculated at each patient visit. ${ }^{57}$ The mean composite local skin reaction scores over time for the ingenol mebutate and vehicle groups in the pooled analyses are summarized in Figure 4. In the face or scalp studies, a mean maximum composite score of approximately 9 for the ingenol mebutate $0.015 \%$ cohort occurred at day 4 and declined to near baseline score by day 15 . Approximately $70 \%$ of patients in the ingenol mebutate $0.015 \%$ cohort had a score of $\geq 3$ for erythema, while scores $\geq 3$ for the other five parameters occurred in only a minority of patients. In the trunk or extremity studies, the mean maximum composite local skin reaction score for the ingenol mebutate $0.05 \%$ group was distributed over days 3 and 8 and declined to the baseline score by day $29 .{ }^{57}$ The majority of patients treated with $0.05 \%$ had scores $\geq 2$ for erythema and flaking or scaling. ${ }^{57}$ Local skin reactions of low to intermediate intensity (maximum composite local skin reaction score $\leq 1-12$ ) occurred in the majority of subjects: $>80 \%$ of patients treated with ingenol mebutate in the face or scalp studies ${ }^{58}$ and $>90 \%$ of patients in the trunk or extremity studies. ${ }^{59}$ Photographs of treatment fields taken at each study visit demonstrate composite local skin reaction scores for three patients at each evaluation (Figure 5).

Pigmentary alterations and scarring were either absent or minimal in all study groups. ${ }^{57}$ Application site reactions were the most commonly reported adverse events with ingenol mebutate in all studies during treatment. In the face or scalp studies, the most common of these reactions were pain $(13.9 \%)$, pruritus $(8.0 \%)$, and irritation $(1.8 \%)$; in the trunk or extremity studies, pruritus $(8.4 \%)$, irritation $(3.6 \%)$, and pain $(2.2 \%)$ were the most frequently reported application site adverse events. One patient in the face or scalp studies withdrew early due to eye pain and edema related to use of ingenol mebutate $0.015 \%$ gel. No serious adverse events occurred that were related to the study treatments. ${ }^{57}$

There were no indications of systemic adverse events associated with ingenol mebutate treatment. A separate study of two daily applications of ingenol mebutate $0.05 \%$ gel to a $100 \mathrm{~cm}^{2}$ surface area of the forearm of 16 patients with AKs demonstrated no systemic absorption above the limit of detection of $0.1 \mathrm{ng} / \mathrm{mL} .{ }^{60}$ Further, local skin reactions in these patients were similar to those observed in the Phase III studies of the $0.05 \%$ gel applied to a $25 \mathrm{~cm}^{2}$ area in terms of their severity and time course. ${ }^{60}$

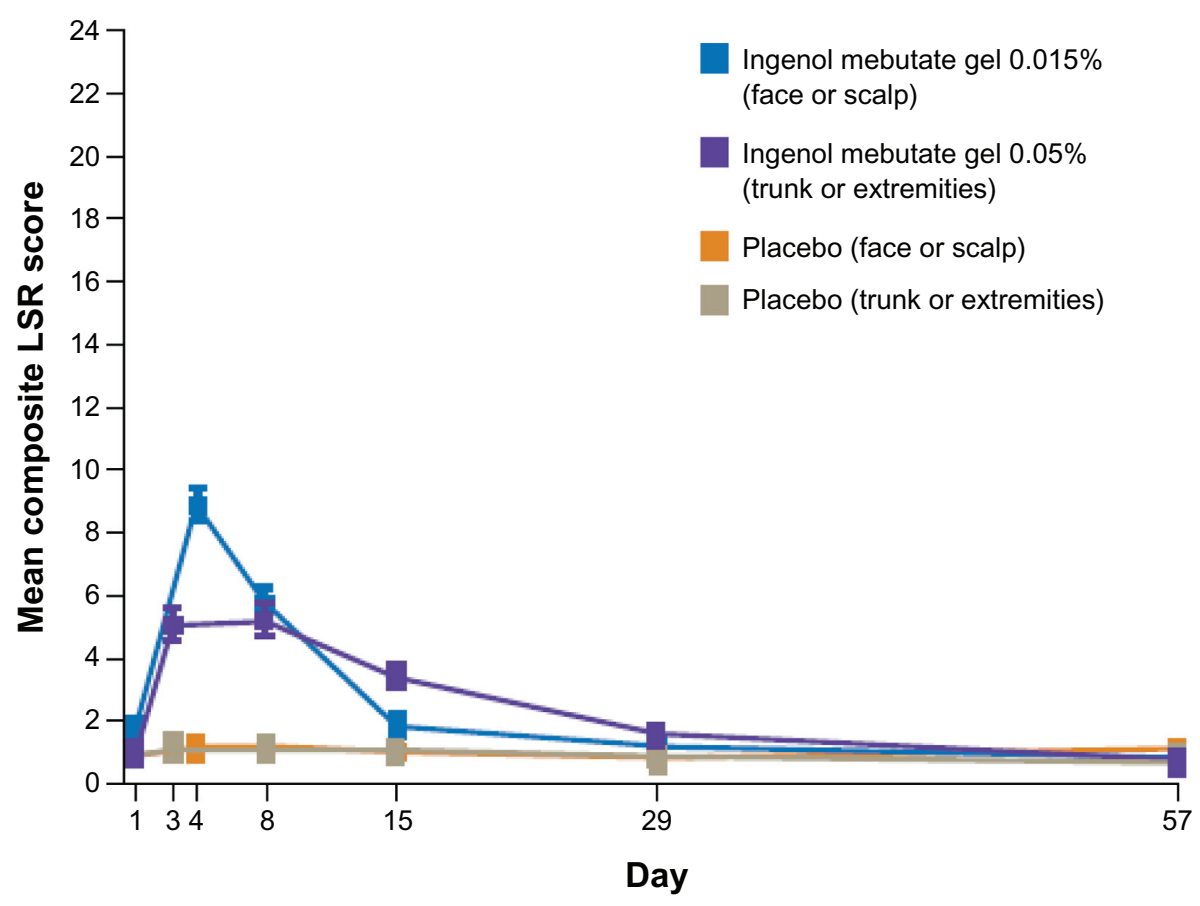

Figure 4 Time course of mean ( \pm standard error of the mean) composite score for local skin reactions from pooled analyses at each study visit. Copyright @ 2012. Massachusetts Medical Society. Reprinted with permission from Massachusetts Medical Society from Lebwohl M, Swanson N, Anderson LL, Melgaard A, Xu Z, Berman B. Ingenol mebutate gel for actinic keratosis. N Engl J Med. 2012;366(II): 10 I0-1019.57

Abbreviation: LSR, local skin reaction. 


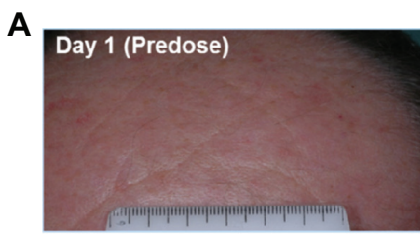

Composite LSR $=0$

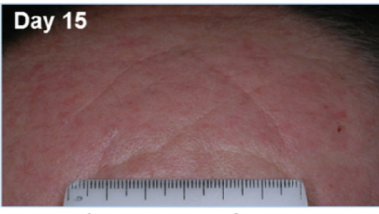

Composite LSR = 2

B

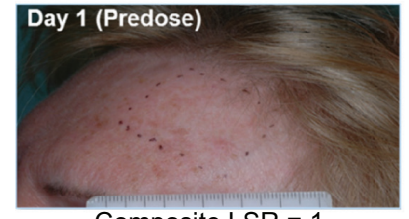

Composite LSR = 1

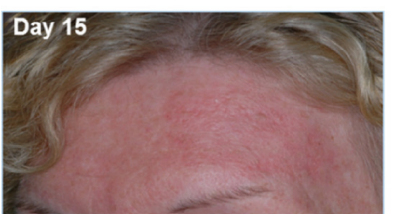

Composite LSR = 2

C

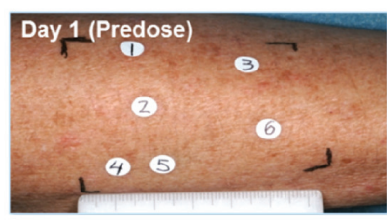

Composite LSR $=0$

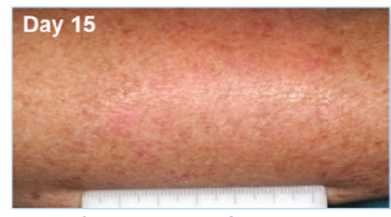

Composite LSR = 2

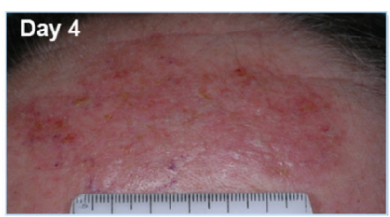

Composite LSR $=10$

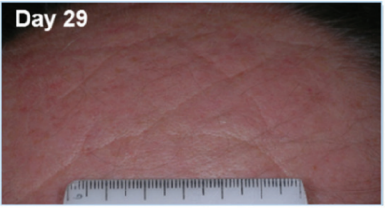

Composite LSR = 0

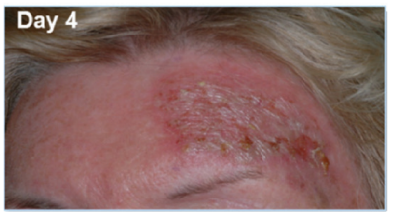

Composite LSR = 19

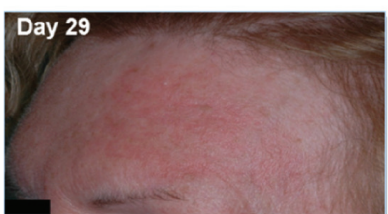

Composite LSR = 2

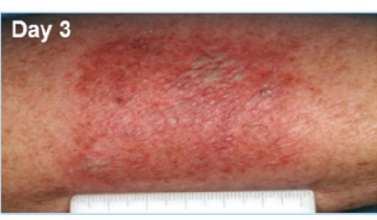

Composite LSR = 12

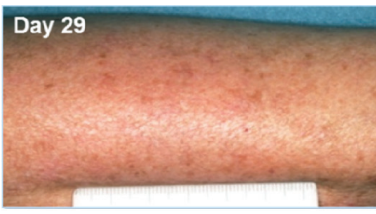

Composite LSR =

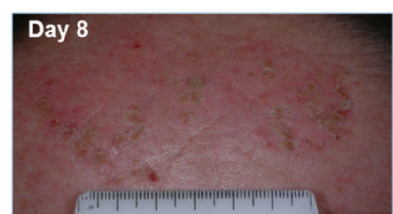

Composite LSR = 8
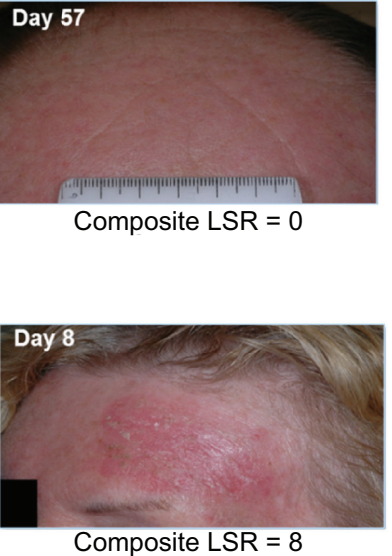

Day 57

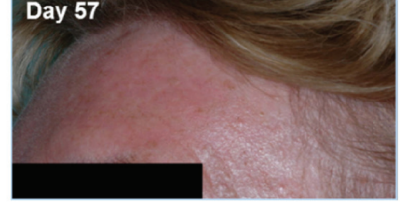

Composite LSR = 1

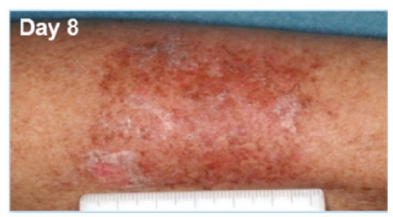

Composite LSR = 5

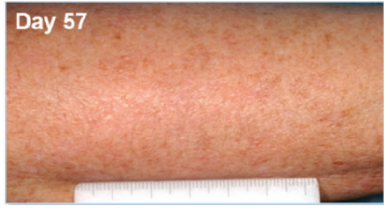

Composite LSR $=0$

Figure 5 Clinical photographs of three patients. Photographs were taken at screening, before treatment on day I, and on days 3 or 4 (one day after last treatment), 8 , 15, 29, and 57. The composite local skin reaction score was calculated at each visit. (A) Forehead lesions. Intermediate peak composite local skin reaction score (I0) on day 4 returned to baseline by day 29. (B) Forehead lesions. High peak composite local skin reaction score (19) on day 4 returned to baseline by day 57 . (C) Arm lesions. Intermediate peak composite local skin reaction score (12) on day 3 returned to baseline by day 57.

Data on file. Clinical study reports PEP005-016 and PEP005-028. Parsippany, NJ: LEO Pharma Inc.; 2010.

Abbreviation: LSR, local skin reaction.

Patients in all ingenol mebutate treatment groups as compared with vehicle groups had significantly higher scores for effectiveness and global satisfaction (measured by Treatment Satisfaction Questionnaire for Medication) and significantly greater improvement in measures of concern for their skin condition (assessed by the Skindex-16 survey) after completion of active treatment. ${ }^{58,59}$

\section{Summary}

$\mathrm{AK}$ is a common disease in sun-damaged skin and is associated with an increased risk of squamous cell carcinoma. While individual risk of annual progression of a single lesion to squamous cell carcinoma is low, most patients with sundamaged skin have many lesions, with a calculated risk of invasive squamous cell carcinoma of up to $10 \%$ over 10 years. 
Treatment of AK is managed with lesion-directed and fielddirected methods, and frequently multiple methods are selected based on the characteristics of the lesions, overall sun damage, and the patient's ability to tolerate treatment. Ingenol mebutate is a new topical field therapy to address this common, chronic skin condition. Ingenol mebutate gel treats AK lesions by a mechanism that includes induction of local lesional cell death and an immune response; however, the mechanism is not fully understood, and continues to be a subject of ongoing study.

Clearance rates with 2-day or 3-day treatment regimens of ingenol mebutate compare well with those achieved with other field therapies that require longer treatment periods. ${ }^{27,28,61-64}$ For example, a complete clearance rate of $43 \%$ was reported with a 4 -week treatment regimen of 5-fluorouracil. ${ }^{28}$ Treatment with imiquimod $2.5 \%$ and $3.75 \%$ produced complete clearance rates that ranged from $25.0 \%$ to $35.6 \%$ after regimens of two 2 -week or 3-week treatment periods, separated by a treatment-free interval of the same time period..$^{27,61}$ The short treatment time and generally mildto-moderate local skin reactions associated with ingenol mebutate may facilitate treatment adherence in patients with AK who have difficulty adhering to longer treatment courses. The studies reviewed here demonstrate that ingenol mebutate gel is highly efficacious, has a good tolerability profile without systemic bioavailability, and is associated with near-absolute treatment adherence in clinical studies. These findings suggest that ingenol mebutate will be a valuable addition to the armamentarium of treatments for AK.

\section{Disclosures}

This manuscript was funded by a grant from LEO Pharma Inc., Parsippany, NJ. Editorial assistance was provided by Tanya MacNeil of $p$-value communications.

\section{References}

1. Drake LA, Ceilley RI, Cornelison RL, et al. Guidelines of care for actinic keratoses. Committee on Guidelines of Care. J Am Acad Dermatol. 1995;32(1):95-98.

2. Society for Investigative Dermatology, American Academy of Dermatology Association. The burden of skin diseases, 2005. Available from: http://www.lewin.com/ /media/lewin/site_sections/publications/ april2005skindisease. Accessed March 12, 2012.

3. Cockerell CJ, Wharton JR. New histopathological classification of actinic keratosis (incipient intraepidermal squamous cell carcinoma). J Drugs Dermatol. 2005;4(4):462-467.

4. Berman B, Bienstock L, Kuritzky L, Mayeaux EJ Jr, Tyring SK. Actinic keratoses: sequelae and treatments. Recommendations from a consensus panel. J Fam Pract. May 2006;55(Supp1 5):1-8.

5. Schwartz RA. The actinic keratosis. A perspective and update. Dermatol Surg. 1997;23(11):1009-1019.
6. Einspahr JG, Alberts DS, Warneke JA, et al. Relationship of p53 mutations to epidermal cell proliferation and apoptosis in human UV-induced skin carcinogenesis. Neoplasia. 1999;1(5):468-475.

7. Toll A, Salgado R, Yebenes M, et al. MYC gene numerical aberrations in actinic keratosis and cutaneous squamous cell carcinoma. Br J Dermatol. 2009;161(5):1112-1118.

8. Toll A, Salgado R, Yebenes M, et al. Epidermal growth factor receptor gene numerical aberrations are frequent events in actinic keratoses and invasive cutaneous squamous cell carcinomas. Exp Dermatol. 2010;19(2):151-153.

9. Kanellou P, Zaravinos A, Zioga M, et al. Genomic instability, mutations and expression analysis of the tumour suppressor genes p14 ${ }^{\mathrm{ARF}}$, p1 $5^{\mathrm{INK} 4 \mathrm{~b}}, \mathrm{p} 16^{\mathrm{INK} 4 \mathrm{a}}$ and $\mathrm{p} 53$ in actinic keratosis. Cancer Lett. 2008;264(1): $145-161$.

10. Padilla RS, Sebastian S, Jiang Z, Nindl I, Larson R. Gene expression patterns of normal human skin, actinic keratosis, and squamous cell carcinoma: a spectrum of disease progression. Arch Dermatol. 2010;146(3):288-293.

11. Marks R, Foley P, Goodman G, Hage BH, Selwood TS. Spontaneous remission of solar keratoses: the case for conservative management. Br J Dermatol. 1986;115(6):649-655.

12. Criscione VD, Weinstock MA, Naylor MF, Luque C, Eide MJ, Bingham SF. Actinic keratoses: natural history and risk of malignant transformation in the Veterans Affairs Topical Tretinoin Chemoprevention Trial. Cancer. 2009;115(11):2523-2530.

13. Dodson JM, DeSpain J, Hewett JE, Clark DP. Malignant potential of actinic keratoses and the controversy over treatment. A patient-oriented perspective. Arch Dermatol. 1991;127(7):1029-1031.

14. Czarnecki D, Meehan CJ, Bruce F, Culjak G. The majority of cutaneous squamous cell carcinomas arise in actinic keratoses. J Cutan Med Surg. 2002;6(3):207-209.

15. Mittelbronn MA, Mullins DL, Ramos-Caro FA, Flowers FP. Frequency of pre-existing actinic keratosis in cutaneous squamous cell carcinoma. Int J Dermatol. 1998;37(9):677-681.

16. Hurwitz RM, Monger LE. Solar keratosis: an evolving squamous cell carcinoma. Benign or malignant? Dermatol Surg. 1995;21(2):184.

17. Feldman SR, Fleischer AB Jr. Progression of actinic keratosis to squamous cell carcinoma revisited: clinical and treatment implications. Cutis. 2011;87(4):201-207.

18. Stockfleth E, Ferrandiz C, Grob JJ, Leigh I, Pehamberger H, Kerl H. Development of a treatment algorithm for actinic keratoses: a European consensus. Eur J Dermatol. 2008;18(6):651-659.

19. Dinehart SM. The treatment of actinic keratoses. JAm Acad Dermatol. 2000;42(1 Pt 2):25-28.

20. Halpern AC, Hanson LJ. Awareness of, knowledge of and attitudes to nonmelanoma skin cancer (NMSC) and actinic keratosis (AK) among physicians. Int J Dermatol. 2004;43(9):638-642.

21. Balkrishnan R, Cayce KA, Kulkarni AS, et al. Predictors of treatment choices and associated outcomes in actinic keratoses: results from a national physician survey study. J Dermatolog Treat. 2006;17(3): 162-166.

22. Thai KE, Fergin P, Freeman M, et al. A prospective study of the use of cryosurgery for the treatment of actinic keratoses. Int J Dermatol. 2004;43(9):687-692.

23. Krawtchenko N, Roewert-Huber J, Ulrich M, Mann I, Sterry W, Stockfleth E. A randomised study of topical 5\% imiquimod vs topical 5-fluorouracil vs cryosurgery in immunocompetent patients with actinic keratoses: a comparison of clinical and histological outcomes including 1-year follow-up. Br J Dermatol. 2007;157 Suppl 2:34-40.

24. Tanghetti E, Werschler P. Comparison of 5\% 5-fluorouracil cream and $5 \%$ imiquimod cream in the management of actinic keratoses on the face and scalp. J Drugs Dermatol. 2007;6(2):144-147.

25. Ulrich M, Krueger-Corcoran D, Roewert-Huber J, Sterry W, Stockfleth E, Astner S. Reflectance confocal microscopy for noninvasive monitoring of therapy and detection of subclinical actinic keratoses. Dermatology. 2010;220(1):15-24. 
26. Rivers JK, Arlette J, Shear N, Guenther L, Carey W, Poulin Y. Topical treatment of actinic keratoses with $3.0 \%$ diclofenac in $2.5 \%$ hyaluronan gel. Br J Dermatol. 2002;146(1):94-100.

27. Swanson N, Abramovits W, Berman B, Kulp J, Rigel DS, Levy S. Imiquimod $2.5 \%$ and $3.75 \%$ for the treatment of actinic keratoses: results of two placebo-controlled studies of daily application to the face and balding scalp for two 2-week cycles. J Am Acad Dermatol. 2010;62(4):582-590.

28. Loven K, Stein L, Furst K, Levy S. Evaluation of the efficacy and tolerability of $0.5 \%$ fluorouracil cream and $5 \%$ fluorouracil cream applied to each side of the face in patients with actinic keratosis. Clin Ther. 2002;24(6):990-1000.

29. Werschler WP. Considerations for use of fluorouracil cream $0.5 \%$ for the treatment of actinic keratosis in elderly patients. $J$ Clin Aesthet Dermatol. 2008;1(2):22-27.

30. Lee AD, Jorizzo JL. Optimizing management of actinic keratosis and photodamaged skin: utilizing a stepwise approach. Cutis. 2009;84(3): $169-175$.

31. Serra-Guillén C, Nagore E, Hueso L, et al. A randomized pilot comparative study of topical methyl aminolevulinate photodynamic therapy versus imiquimod 5\% versus sequential application of both therapies in immunocompetent patients with actinic keratosis: clinical and histologic outcomes. J Am Acad Dermatol. 2012;66(4):e131-e137.

32. Berlin JM, Rigel DS. Diclofenac sodium 3\% gel in the treatment of actinic keratoses postcryosurgery. J Drugs Dermatol. 2008;7(7):669-673.

33. Tan JK, Thomas DR, Poulin Y, Maddin F, Tang J. Efficacy of imiquimod as an adjunct to cryotherapy for actinic keratoses. J Cutan Med Surg. 2007;11(6):195-201.

34. Jorizzo JL, Markowitz O, Lebwohl MG, et al. A randomized, doubleblinded, placebo-controlled, multicenter, efficacy and safety study of $3.75 \%$ imiquimod cream following cryosurgery for the treatment of actinic keratoses. J Drugs Dermatol. 2010;9(9):1101-1108.

35. Jorizzo J, Weiss J, Vamvakias G. One-week treatment with $0.5 \%$ fluorouracil cream prior to cryosurgery in patients with actinic keratoses: a double-blind, vehicle-controlled, long-term study. J Drugs Dermatol. 2006;5(2):133-139.

36. Picato (ingenol mebutate) gel $0.015 \%, 0.05 \%$ [package insert]. Parsippany, NJ: LEO Pharma Inc.; 2012.

37. Weedon D, Chick J. Home treatment of basal cell carcinoma. Med J Aust. 1976;1(24):928.

38. Green AC, Beardmore GL. Home treatment of skin cancer and solar keratoses. Australas J Dermatol. 1988;29(3):127-130.

39. Ramsay JR, Suhrbier A, Aylward JH, et al. The sap from Euphorbia peplus is effective against human nonmelanoma skin cancers. $\mathrm{Br} J$ Dermatol. 2011;164(3):633-636.

40. Zibert JR, Bertelsen M, Grue-Sørensen G, et al. Ingenol mebutate penetrates reconstructed human skin in a gradient dependent manner and clears subclinical skin cancer. Poster P5501 presented at the Annual Meeting of the American Academy of Dermatology, March 16-20, 2012, San Diego, CA.

41. Ogbourne SM, Suhrbier A, Jones B, et al. Antitumor activity of 3-ingenyl angelate: plasma membrane and mitochondrial disruption and necrotic cell death. Cancer Res. 2004;64(8):2833-2839.

42. Stahlhut M, Lord JM, Bertelsen M, et al. Ingenol mebutate initiates multiple specific cell death pathways in human cancer cells. Poster P5517 presented at the Annual Meeting of the American Academy of Dermatology, March 16-20, 2012, San Diego, CA.

43. Kedei N, Lundberg DJ, Toth A, Welburn P, Garfield SH, Blumberg PM. Characterization of the interaction of ingenol 3-angelate with protein kinase C. Cancer Res. 2004;64(9):3243-3255.

44. Hampson P, Chahal H, Khanim F, et al. PEP005, a selective small-molecule activator of protein kinase $\mathrm{C}$, has potent antileukemic activity mediated via the delta isoform of PKC. Blood. 2005;106(4):1362-1368.

45. Serova M, Ghoul A, Benhadji KA, et al. Effects of protein kinase C modulation by PEP005, a novel ingenol angelate, on mitogen-activated protein kinase and phosphatidylinositol 3-kinase signaling in cancer cells. Mol Cancer Ther. 2008;7(4):915-922.
46. Benhadji KA, Serova M, Ghoul A, et al. Antiproliferative activity of PEP005, a novel ingenol angelate that modulates PKC functions, alone and in combination with cytotoxic agents in human colon cancer cells. Br J Cancer. 2008;99(11):1808-1815.

47. Challacombe JM, Suhrbier A, Parsons PG, et al. Neutrophils are a key component of the antitumor efficacy of topical chemotherapy with ingenol-3-angelate. J Immunol. 2006;177(11):8123-8132.

48. Li L, Shukla S, Lee A, et al. The skin cancer chemotherapeutic agent ingenol-3-angelate (PEP005) is a substrate for the epidermal multidrug transporter (ABCB1) and targets tumor vasculature. Cancer Res. 2010;70(11):4509-4519.

49. Fecker LF, Stockfleth E, Braun FK, et al. Enhanced death ligandinduced apoptosis in cutaneous SCC cells by treatment with diclofenac/ hyaluronic acid correlates with downregulation of c-FLIP. J Invest Dermatol. 2010;130(8):2098-2109.

50. Hampson P, Kavanagh D, Smith E, Wang K, Lord JM, Ed RG. The anti-tumor agent, ingenol-3-angelate (PEP005), promotes the recruitment of cytotoxic neutrophils by activation of vascular endothelial cells in a PKC-delta dependent manner. Cancer Immunol Immunother. 2008;57(8):1241-1251.

51. Le TT, Gardner J, Hoang-Le D, et al. Immunostimulatory cancer chemotherapy using local ingenol-3-angelate and synergy with immunotherapies. Vaccine. 2009;27(23):3053-3062.

52. Lee WY, Hampson P, Coulthard L, et al. Novel antileukemic compound ingenol 3-angelate inhibits $\mathrm{T}$ cell apoptosis by activating protein kinase C theta. J Biol Chem. 2010;285(31):23889-23898.

53. Cozzi SJ, Ogbourne SM, James C, et al. Ingenol mebutate field-directed treatment of UVB-damaged skin reduces lesion formation and removes mutant p53 patches. J Invest Dermatol. 2012;132(4):1263-1271.

54. Kane-Maguire N, Cozzi SJ, Ogbourne SM, Mosely R. Modulation of fibroblast phenotype and extracellular matrix composition by ingenol mebutate may be associated with scar resolution and improved dermal cosmesis. Poster P5350 presented at the Annual Meeting of the American Academy of Dermatology, March 16-20, 2012, San Diego, CA.

55. Siller G, Gebauer K, Welburn P, Katsamas J, Ogbourne SM. PEP005 (ingenol mebutate) gel, a novel agent for the treatment of actinic keratosis: results of a randomized, double-blind, vehicle-controlled, multicentre, Phase IIa study. Australas J Dermatol. 2009;50(1):16-22.

56. Anderson L, Schmieder GJ, Werschler WP, et al. Randomized, doubleblind, double-dummy, vehicle-controlled study of ingenol mebutate gel $0.025 \%$ and $0.05 \%$ for actinic keratosis. J Am Acad Dermatol. 2009;60(6):934-943.

57. Lebwohl M, Swanson N, Anderson LL, Melgaard A, Xu Z, Berman B. Ingenol mebutate gel for actinic keratosis. $N$ Engl J Med. 2012;366(11):1010-1019.

58. Berman B, Marmur E, Melgaard A. Three-day topical treatment with ingenol mebutate gel $0.015 \%$ for actinic keratoses on the face and scalp: analysis of data pooled from two trials. Poster P5623 presented at the Annual Meeting of the American Academy of Dermatology, March 16-20, 2012, San Diego, CA.

59. Anderson LL, Schmeider GJ, Xu Z, Melgaard A. Two-day topical treatment with ingenol mebutate gel $0.05 \%$ for actinic keratoses on the trunk and extremities: analysis of data pooled from two trials. Poster P5640 presented at the Annual Meeting of the American Academy of Dermatology, March 16-20, 2012, San Diego, CA.

60. Jarratt M. A randomized, double-blind, vehicle-controlled study to evaluate the pharmacokinetics of PEP005 (ingenol mebutate) gel, $0.05 \%$, when applied to dorsal forearms with multiple actinic keratoses (AK) in a maximal-use setting, defined as a contiguous $100-\mathrm{cm}^{2}$ area of skin. Poster presented at the 7th Annual Orlando Dermatology Aesthetic and Clinical meeting, January 15-18, 2010, Orlando, FL.

61. Hanke CW, Beer KR, Stockfleth E, Wu J, Rosen T, Levy S. Imiquimod $2.5 \%$ and $3.75 \%$ for the treatment of actinic keratoses: results of two placebo-controlled studies of daily application to the face and balding scalp for two 3-week cycles. J Am Acad Dermatol. 2010;62(4): $573-581$. 
62. Wolf JE Jr, Taylor JR, Tschen E, Kang S. Topical 3.0\% diclofenac in $2.5 \%$ hyaluronan gel in the treatment of actinic keratoses. Int $J$ Dermatol. 2001;40(11):709-713.

63. Rivers JK, Arlette J, Shear N, Guenther L, Carey W, Poulin Y. Topical treatment of actinic keratoses with 3.0\% diclofenac in $2.5 \%$ hyaluronan gel. Br J Dermatol. 2002;146(1):94-100.
64. Weiss J, Menter A, Hevia O, et al. Effective treatment of actinic keratosis with $0.5 \%$ fluorouracil cream for 1 , 2, or 4 weeks. Cutis. 2002; 70(Suppl 2):22-29.

\section{Publish your work in this journal}

Clinical, Cosmetic and Investigational Dermatology is an international, peer-reviewed, open access, online journal that focuses on the latest clinical and experimental research in all aspects of skin disease and cosmetic interventions. All areas of dermatology will be covered; contributions will be welcomed from all clinicians and basic science researchers globally. This journal is indexed on CAS

The manuscript management system is completely online and includes a very quick and fair peer-review system, which is all easy to use. Visit http://www.dovepress.com/testimonials.php to read real quotes from published authors.

Submit your manuscript here: http://www.dovepress.com/clinical-cosmetic-and-investigational-dermatology-journal 